\title{
Políticas de formação de professores na universidade pública: uma análise de necessidades, entre o local e o global
}

\section{Teacher education policy in public universities: an analysis of the needs, between local and global}

\author{
Maria Amélia S. Zainko
}

\begin{abstract}
RESUMO
O presente texto busca trazer para o debate aspectos das políticas de formação em desenvolvimento nas universidades, bem como a influência significativa no fazer acadêmico, trazidas pelas tendências internacionais. Destaca que o século XXI acentuou enormemente a importância do contexto mundial e as consequências da "mundialização" sobre os processos de formação na educação superior, que não podem mais ser pensados nos limites das fronteiras nacionais. Analisa a política de expansão da educação superior colocada em prática no Governo do Presidente Luis Inácio Lula da Silva a partir de um conjunto de dados disponíveis no Observatório da Educação, mais especificamente no projeto Políticas de Formação do Professor e a Qualidade da Educação Básica, em desenvolvimento no âmbito do Programa de Pós-Graduação em Educação da Universidade Federal do Paraná (UFPR). Os dados permitem a constatação de que ainda estamos longe de cumprir as metas preconizadas pelo Plano Nacional de Educação. Os dados do Censo da Educação Superior de 2007 apontam uma taxa de escolarização bruta de $21,6 \%$ de alunos na faixa etária de 18 a 24 anos e uma taxa liquida de 12,9\%, quando a meta seria atingir a $30 \%$ de escolarização até o ano de 2011. O texto apresenta ainda as ações estratégicas que vem sendo desenvolvidas para minimizar os déficits e traz para o debate os desafios apresentados por estudiosos e dirigentes na Conferência Mundial de Educação Superior com especial ênfase no papel que a formação dos professores assume no momento em que o paradigma de educação superior aponta para a necessidade de ir além das palavras. Palavras-chave: Educação Superior; Formação de Professores; Políticas de Formação.
\end{abstract}

1 Doutora em Educação. Professora/pesquisadora do Programa de Pós-Graduação em Educação - Universidade Federal do Paraná, Brasil. 


\begin{abstract}
The present text intends to discuss the teacher training issues being developed in universities, as well as the meaningful influence in the academic actions brought about by international trends. It stresses that the XXI century greatly emphasized the importance of global context and consequences of "globalization" on education processes in higher education, which can no longer be thought within the limits of national borders. It analyzes the expansion policy of higher education put into practice in the government of President Luis Inácio Lula da Silva from a set of available data in the Education Observatory, specifically in the project Teacher Training Policies and Quality of Basic Education, being developed within the Graduation Program in Education at Universidade Federal do Paraná (UFPR). The data lead to the conclusion that we are still far from achieving the goals established by the National Education Plan. The 2007 data from the Higher Education Census indicates a gross enrollment ratio of $21.6 \%$ of students aged 18 to 24 and a net rate of $12.9 \%$ when the target would be to reach $30 \%$ by the year 2011 . The text also presents the strategic actions that have been developed to minimize the deficits and bring to the debate the challenges presented by scholars and leaders at the World Conference on Higher Education with special emphasis on the role that teacher training takes at the time the higher education paradigm points to the need of going beyond the words. Keywords: Higher Education; Teacher Training; Training Policies.
\end{abstract}

\title{
Introdução
}

A análise das políticas de formação em desenvolvimento nas universidades, em especial nas universidades públicas, requer a aceitação tácita de que tanto na graduação, como na pós-graduação as tendências internacionais exercem influência significativa no fazer acadêmico.

O século XXI acentuou enormemente a importância do contexto mundial de tal sorte que hoje os estudiosos das questões acadêmicas destacam em seus estudos e investigações as consequências da "mundialização" sobre os processos de formação na educação superior, que não podem mais ser pensados nos limites das fronteiras nacionais. 
Os exemplos do movimento de revisão desencadeado na Europa a partir do Processo de Bolonha implantado em 1999, e que ao completar 10 anos apresenta reflexões importantes sobre os resultados possíveis na reconfiguração de sistemas de educação superior com exigências locais diferenciadas, e do ENLACES como perspectiva de construção de um espaço comum latino-americano para responder as exigências de uma educação superior que congregue necessidades globais com os desafios cotidianos dos problemas locais, dão bem a dimensão da importância da internacionalização no papel a ser desempenhado pelas instituições de educação superior.

A verdade é que, não obstante a enorme gama de estudos e os espaços de reflexões nacionais e internacionais, a missão básica da educação superior permanece vinculada a quatro objetivos principais:

1- a produção de novos conhecimentos (função de pesquisa);

2- a formação de pessoal altamente qualificado (função de ensino);

3- a prestação de serviços à sociedade;

4- a função ética, que inclui a crítica social.

Os debates que têm sido travados deixam claro que face ao avanço da ciência e da tecnologia os representantes dos países industrializados, de há muito conscientes de que o saber, o conhecimento e a informação tornaram-se os elementos motores da sociedade mundial, buscam todas as formas de defesa do acesso universal à educação Superior.

Mas, não há que confundir informação com conhecimento. Informação é um conjunto de dados ao qual se tem acesso. O conhecimento pressupõe uma capacidade crítica de aprendizagem, que permite a transformação do arquivo de informações em conhecimento útil, e com capacidade de gerar a transformação.

Na área política, esta distinção é essencial para a tomada de decisões e na área econômica, a distinção fundamental efetua-se entre quem concebe os produtos industriais - o que é de longe o mais importante- e sua produção. A concepção é diretamente ligada à pesquisa e ao desenvolvimento baseado sobre a ciência e a codificação do saber teórico, enquanto que a produção o é muito menos. Quanto mais tecnologia agregada tem um produto, maior é o seu preço, mais empregos são gerados na sua fabricação. Por isto, os países ricos investem na pesquisa científica e tecnológica.

É evidente que para atingir um estado de maior desenvolvimento endógeno, autossustentável, humano ou apenas para ser independente, os países em desenvolvimento, em particular os da América Latina, necessitam de mais conhecimento, de mais tecnologia. O conhecimento é produzido basicamente nas universidades e quem desenvolve tecnologias são os cidadãos formados nos estabelecimentos de ensino superior, os cientistas, os engenheiros, os pesquisadores, os cientistas sociais e os educadores. 


\section{Políticas de formação na Universidade Pública}

Assim a nova política de formação nas universidades e em especial nas universidades públicas que são as que têm um compromisso inarredável com o atendimento à maioria da população, não pode prescindir de dois elementos fundamentais: a qualidade e a pertinência.

Qualidade e pertinência são conceitos interligados e esse último deve medir-se pela adequação entre o que fazem os estabelecimentos de ensino superior e o que espera deles a sociedade.

Neste marco, a pertinência, a participação na busca de solução aos grandes problemas da sociedade (erradicação da pobreza, da intolerância, da violência, do analfabetismo, da deterioração do meio ambiente e das enfermidades), a integração com o mundo do trabalho, onde as necessidades das sociedades sejam consideradas prioritárias e a contribuição ao desenvolvimento do conjunto do sistema educacional, são essenciais na ação dos estabelecimentos e dos sistemas de ensino superior.

O contexto atual da reforma universitária brasileira e os projetos de expansão e reestruturação em desenvolvimento refletem os compromissos de um governo empenhado no redirecionamento das políticas sociais e, portanto, tem nas suas instituições universitárias a base de sustentação para o cumprimento da mais fundamental missão da sociedade contemporânea, qual seja o combate as mais perversas doenças sociais do nosso tempo: a marginalização e a exclusão sociais.

Neste sentido, é fundamental que a "nova" universidade tenha como compromisso fazer com que a Educação Superior, tendo a pesquisa como seu princípio educativo, seja parte integrante e ativa do desenvolvimento cultural, socioeconômico e ecologicamente sustentável das pessoas, das comunidades e das nações.

Uma Universidade de inclusão social deve participar de maneira decidida da melhoria qualitativa de todos os níveis do sistema educativo, principalmente no que tange: a formação com atualização docente; a transformação dos alunos em agentes ativos de sua própria formação; a promoção da pesquisa socioeducativa e a elaboração de políticas públicas no campo da Educação em geral, aí incluídos: o ensino fundamental e médio.

Com uma proposta marcadamente comprometida com a inclusão social, as políticas sociais do atual governo, no campo da educação superior, buscam atender, entre outros, o princípio da internacionalidade e interatividade, segundo o qual as universidades e as instituições de educação superior deverão manter co- 
laboração permanente com outras similares nacionais, internacionais e institutos de pesquisa, no ensino, na pesquisa e extensão, em distintos projetos de interesse comum, conciliando o caráter universal da ciência e dos valores fundamentais da humanidade com as características e necessidades locais ou regionais.

No momento em que a Educação Superior sofre as influências do processo de globalização da economia e da consequente queda das fronteiras do conhecimento, mais e mais espaços se abrem para os intercâmbios de conhecimentos seja ao nível do processo de formação em nível de graduação, seja ao nível da pós-graduação.

O estreitamento das relações culturais intra e inter-países têm se constituído em um elemento favorecedor da mobilidade acadêmica e da qualidade do processo de formação.

Por isso, hoje é de fundamental importância que na aplicação de Diretrizes Curriculares e na revisão dos projetos pedagógicos dos cursos, as possibilidades de intercâmbios sejam consideradas como elementos inerentes ao processo de aprendizagem de alunos e professores. É, portanto, uma ação que não se esgota apenas nas relações diplomáticas e nos tratados de amizade entre os povos, mas na discussão e na atualização dos processos de formação em nível superior. Essa prática estabelecerá novas bases para a normalização da Educação Superior no País.

O documento base proposto Pelo Conselho Nacional de Educação - CNE - em Fórum Nacional da Educação Superior realizado para ouvir a comunidade acadêmica e para discutir a participação do Brasil na Conferência Mundial de Educação Superior, realizada em Paris no período 5 a 8 de julho de 2009, enfatizava a necessidade de ampliação do acesso à educação superior e preconizava uma universidade comprometida com a inclusão social.

Uma inclusão social decorrente de um forte esforço de expansão da oferta e de um explícito compromisso da Universidade com o desenvolvimento de ações afirmativas, políticas de avaliação e busca incessante da qualidade acadêmica.

A melhoria da qualidade da educação superior, a orientação da expansão da sua oferta, o aumento permanente da sua eficácia institucional e efetividade acadêmica e social, e, especialmente, a promoção do aprofundamento dos compromissos e responsabilidades sociais das instituições de educação superior, fazem parte da proposta de avaliação institucional colocada em prática segundo as orientações do SINAES (PORTARIA MEC N. 2.051/04, art. $1^{\circ}$ ).

O SINAES nos leva a conduzir estudos que viabilizem um novo olhar sobre a essência de uma proposta de fazer universitário como elemento de sustentação de uma política de qualidade e inclusão social formulando estratégias de ação que garantam as universidades como espaços públicos de educação e (in) formação de cidadãos. 
Uma Universidade com menos evasão e mais responsabilidade social por parte dos alunos, professores e servidores se apresenta como exigência do tempo presente, quer seja pelo impacto da explosão do conhecimento nos processos formativos, quer seja pela necessidade da universidade repartir com a população que a criou e mantém os resultados de suas pesquisas e toda produção do conhecimento que se dá nas salas de aulas e nos laboratórios, contribuindo assim de maneira decisiva para a resolução dos problemas locais, regionais e nacionais.

\section{A Expansão da Educação Superior}

A política atual de expansão da educação superior no Brasil leva em conta as metas traçadas no Plano Nacional de Educação - PNE - que estabelecem os compromissos de matricular 30\% da população da faixa etária apropriada, ou seja 18 a 24 anos, até 2011 e de ter $40 \%$ das matrículas em instituições de educação superior feitas em instituições públicas.

Historicamente, e em especial nas últimas quatro décadas, a educação superior no Brasil passou por duas fases de forte expansão. A primeira delas coincidiu exatamente com o período militar. De 1964 a 1980, o número de matrículas nesse nível de ensino aumentou quase dez vezes. Contraditoriamente, no período subseqüente, de abertura política e redemocratização do país (19801995), o sistema apresentou um crescimento meramente vegetativo.

Em 1980, havia 882 instituições de ensino superior no país. Em 1995, apenas 12 instituições tinham se agregado ao sistema, contabilizando um modesto crescimento de $1.36 \%$ no período (MACEDO, 2005, p. 3 ).

A segunda fase de forte expansão se iniciou a partir de 1996. Em uma década (1996-2007), segundo dados do Censo da Educação Superior 2007, outras 1387 novas escolas de nível superior foram criadas. O aumento do número de instituições desencadeou uma elevação do número de matrículas, que chegou a 4.880.381 alunos matriculados em 2007. Porém esse crescimento se deu majoritariamente na educação superior privada, de tal sorte que desse total 25,4\% das matrículas são em instituições públicas e 74,6\% em instituições privadas. O ano de 1996, com a aprovação da Lei de Diretrizes e Bases da Educação e com a criação dos Centros Universitários como uma nova forma de organização acadêmica, inaugurou uma nova fase da história da educação superior no Brasil. A partir desse ano o sistema privado começou a se expandir numa velocidade inédita. 
Temos, segundo dados do Censo da Educação Superior de 2007, um sistema em expansão, com $89 \%$ das Instituições privadas e configuradas como de pequeno porte, sendo $8 \%$ de Universidades e $92 \%$ de outras organizações acadêmicas, o que define um sistema de educação superior diversificado, mas não universitário.

Apesar do setor público (rede municipal, estadual e federal) ter ampliado consideravelmente o número de matrículas a partir de 1996, a grande contribuição para a ampliação do sistema foi dada pela iniciativa privada. O esforço realizado pelas instituições federais para aumentar a oferta de vagas, a partir da segunda metade da década de 1990, ocorreu a despeito da falta de investimentos do Estado brasileiro na educação superior pública.

Com a proposta de fazer das metas do PNE uma realidade, o Governo Lula vem realizando desde 2003 um importante movimento de recuperação do orçamento das universidades federais, e em 2007 deu início a um vigoroso processo de expansão, com a implantação de novas unidades acadêmicas distribuídas por todo o território nacional, e a criação de 14 novas universidades, dentre as quais destacam-se a UNILA (Universidade de integração latino-americana) a UNILAB (Universidade Luso- afro-brasileira) e a Universidade da Fronteira Sul. Denominado de REUNI, (reestruturação das Universidades) o programa de expansão em vigência, em termos orçamentários, considerando-se os recursos do Tesouro na dotação inicial de 2007, promoveu um aumento global de 31,5\% em termos reais quando comparados à execução orçamentária de 2002. Nesse período, o investimento nas universidades aumentou 905\%, o custeio teve um aumento de $63,5 \%$, e houve um acréscimo de $21,9 \%$ em pessoal. Por meio do REUNI o Ministério da Educação reafirma seu compromisso com a universidade pública, gratuita e de qualidade.

Com uma taxa de escolarização bruta de $21,6 \%$ da população na faixa etária de 18 a 24 anos e com uma taxa de escolarização líquida de 12,9\% há muito ainda a ser feito para o alcance das metas do PNE.

Por isso, não obstante sua oportunidade e pertinência, a expansão do sistema público federal de educação superior deve estar associada a reestruturações acadêmicas e curriculares que proporcionem maior mobilidade estudantil, trajetórias de formação flexíveis, redução das taxas de evasão, utilização adequada dos recursos humanos e materiais colocados à disposição das universidades federais.

Este movimento visa a consolidar e aperfeiçoar o sistema público de educação superior, com destaque para a revisão de currículos e projetos acadêmicos visando a flexibilizar e melhorar a qualidade da educação superior, bem como proporcionar aos estudantes formação multi e interdisciplinares, humanista e com o desenvolvimento do espírito crítico. 
É neste sentido que ganha destaque a formação de professores e assistimos a um regresso da questão ao centro das preocupações educativas, pois são eles os maiores responsáveis pela transformação demandada pela educação superior.

\section{A formação dos professores entre o global e o local}

O educador português Antonio Nóvoa ao discutir a formação de professores assegura que:

[...] os professores reaparecem, neste início de século XXI, como elementos insubstituíveis não só na promoção das aprendizagens, mas também na construção de processos de inclusão que respondam aos desafios da diversidade e no desenvolvimento de métodos apropriados de utilização das novas tecnologias ( NÓVOA, 2009, p. 24).

Isto nos leva a refletir sobre a necessidade imediata da revisão da formação acadêmica que se apresenta como um dos maiores desafios para a garantia da qualidade em uma universidade comprometida com a inclusão social e com a inovação. Neste sentido acrescenta-se às tradicionais funções universitárias de ensino, pesquisa e extensão a de incorporar nos projetos pedagógicos dos cursos a gestão do conhecimento como um desafio ao processo de aperfeiçoamento constante da formação inicial e continuada dos profissionais que as IES colocam a serviço da sociedade.

O conhecimento em ação, uma das características do nosso tempo, requer para a manutenção de um processo permanente de aperfeiçoamento a utilização de ferramentas que nos possibilitem estar em dia com as últimas descobertas e com a capacidade de transformar dados em informações úteis.

A formação de todos os profissionais deve estar atenta a essas novas demandas e a formação de professores em especial não pode prescindir dessa perspectiva de aperfeiçoamento constante. A sistemática atual da formação, no entanto, transforma isso em um grande desafio. É preciso estar sintonizado com a necessidade de levar para os processos de formação dados da realidade e instrumentos eficazes de gerenciamento do conhecimento.

A Gestão do conhecimento significa organizar e sistematizar, em todos os pontos de contato internos e externos, a capacidade individual e coletiva de 
captar, gerar, criar, analisar, traduzir, transformar, modelar, armazenar, disseminar, implantar e gerenciar a informação, tanto interna como externa. Essa informação deve ser transformada efetivamente em conhecimento e distribuída, tornando-se acessível aos interessados.

A gestão do conhecimento na formação dos professores é um processo sistemático, articulado e intencional, de disseminação e apropriação de conhecimento e tem o propósito de atingir a excelência da formação e por consequência a qualidade da educação.

A importância especial que tem a escola como ambiente social nos países em desenvolvimento, a escassez de espaços públicos de lazer e a cultura e convivência social saudável para crianças e jovens fazem recair sobre a escola, com grande frequência, a responsabilidade de ser a única referência positiva de sociabilidade e formação para esse grupo. Esse fato traz vantagens e desafios para as escolas. Cabe a nós, portanto, perguntar não só que escola queremos, mas o que fazer de modo a contribuir para que ela cumpra o seu papel. E, evidentemente, que professor nós queremos para essa escola.

Não se trata aqui de fazer apologia à construção de um projeto único de formação, ignorando a diversidade e as especificidades de cada região, estado e comunidade. Ao contrário, o que se espera é que a escola, em cada local, assuma contornos próprios a partir do diálogo com a realidade em que está inserida. A autonomia da escola para construir o seu projeto político-pedagógico deve ser mais do que respeitada, estimulada. E os educadores são os responsáveis por elaborar e colocar em prática esse projeto.

Assumir tal responsabilidade implica também em exigir das instituições formadoras o repensar de seus processos de formação, atualizando-os e colocando-os em sintonia com as exigências do desenvolvimento científico e tecnológico e com as demandas da sociedade, já que investir na formação de professores é essencial para que haja transformações na escola.

O processo formativo permanente dos professores, que inclui tanto a formação inicial como sua continuidade ao longo de toda a vida do profissional, não é um fim em si mesmo, mas um meio de contribuir para a melhoria da qualidade do ensino na escola.

No Brasil, o propósito da Lei de Diretrizes e Bases da Educação (Art. 62), ao exigir que os professores da educação básica tenham formação de nível superior - embora admitindo o curso normal de nível médio para a educação infantil e os quatro anos iniciais do ensino fundamental - é o de melhorar a qualidade da educação oferecida aos cidadãos brasileiros. A ideia de formação em nível superior é reforçada pelo artigo 87 da mesma Lei, segundo o qual cabe aos Municípios, aos Estados e à União realizar programas de capacitação para todos os professores em exercício, utilizando também, para isso os recursos da 
educação a distância. A preocupação com a formação dos professores em nível superior manifesta-se, ainda, no Plano Nacional de Educação, aprovado pela Lei n. 10.172/2001, que definiu como meta para o decênio contar com, pelo menos, 70\% dos docentes em exercício na educação básica formados em nível de graduação.

Segundo Miranda e Salgado ${ }^{2}$, não obstante as diversas iniciativas do MEC na formulação de políticas públicas no campo da educação presencial e não presencial destinadas à capacitação sistemática de professores, para atender às necessidades do País, ainda existe elevado número de pessoas com formação insuficiente atuando na educação básica no Brasil. Por isso, o PLANFOR lançado em 2009 tem como compromisso fundamental atuar sobre os problemas de ausência de formação e da formação inadequada em nível superior.

É também uma forma de reduzir as dificuldades no cumprimento das metas do PNE e ao mesmo tempo responder aos desafios de promover a expansão do acesso à educação superior, com a flexibilização dos modelos de formação vigentes, ao mesmo tempo que incentiva a elevação da qualidade e a avaliação numa universidade comprometida com o desenvolvimento humano e social.

Embora, como afirma Cury (1997) se possa dizer, genericamente, que uma profissão se qualifica por tudo que se promova em favor dela, é preciso distinguir a formação de outros processos com igual horizonte.

\begin{abstract}
A qualificação é uma relação social que envolve o coletivo e a relação entre educação e trabalho. Como em toda profissão, essa relação possui uma dimensão formativa inicial: aquela que possibilita a uma categoria o exercício profissional. No caso dos docentes, a formação inicial completa em estabelecimentos regulares e credenciados é uma licença que, por sua vez, faz do seu portador, e só dele, alguém capaz de ingressar nas redes de educação escolar dos sistemas de ensino. Portanto, a qualificação implica uma formação sistemática, regular e regulamentada, que, quando obtida em estabelecimentos escolares reconhecidos, gera um diploma ao seu portador. Ela tem um caráter coletivo e institucional (CURY, 1997).
\end{abstract}

Por melhor e mais avançado que seja um curso de formação acadêmica, o professor, como qualquer profissional, não sai "pronto" da universidade, mas tem necessidade de complementar, aprimorar e atualizar seus conhecimentos, na prática. Na perspectiva da epistemologia contemporânea, a prática não

2 Miranda, G e Salgado, M.U.C Proposta de Formação de Professores, Secretaria de Educação de Minas Gerais, Veredas, 2000. 
constitui mero campo de aplicação da teoria aprendida na universidade, pois o conhecimento se produz também na própria prática.

Assim, ainda conforme análise de Miranda e Salgado, formação inicial e continuada fazem parte de um processo contínuo que forma o profissional da educação e, ao mesmo tempo, a profissão de educador e a própria escola. Ambas as dimensões - inicial e continuada - apoiam-se em princípios e pressupostos comuns, considerando o aluno/professor como sujeito, valorizando suas experiências pessoais e seus saberes da prática. Apoiam-se no trabalho coletivo e compartilhado, mas isso não exclui, ao contrário, exige o desenvolvimento e o compromisso individual.

Além disso, no atual contexto de produção cada vez mais acelerada de conhecimentos científicos, não se pode esquecer a importância da atualização permanente, de forma a democratizar o acesso de todos os profissionais aos progressos do seu campo de trabalho.

Assim, tomar a formação inicial docente em si, com suas precariedades e virtudes, como fonte para analisar, criticar, elogiar, avaliar enfim a atuação dos docentes em exercício na educação básica é incorrer no erro lógico de tomar uma manifestação importante e significativa como se ela fosse o todo. Logicamente, qualquer avaliador sabe que a formação inicial é a condição e o meio mais próximo e direto para o exercício profissional em sala de aula. Portanto, ela deve ser a melhor possível e a mais adequada ao perfil dos estudantes de modo que o princípio do acesso e permanência na escola dos estudantes seja o mais universal e também o melhor.

Entretanto, há autores, como Tardif, que defendem que os saberes nascidos do fazer também têm de ser objeto de valorização sistemática, o que nem sempre acontece. O momento dessa valorização implica uma iniciativa que possibilite uma organização mais clara e mais sistemática que signifique um momento de retomada e de reflexão de experiências e questionamento de rotinas.

A formação continuada permite, então, que o professor vá se apropriando como sujeito dos conhecimentos que ele mesmo gerou e que se torne um professor investigador que pode rever sua prática, atribuir-lhe novos significados e obter maior espaço para a compreensão das mudanças que o atingem. Além disso, os desafios atuais do mundo contemporâneo implicam um conhecimento teórico-prático de uma sociedade em que a sala de aula se projeta, por exemplo pela rede mundial de computadores, para além das quatro paredes.

É preciso lembrar que formação inicial é sempre algo absolutamente indispensável, já que é a base de sustentação de um processo formativo continuado, capaz de articular essa formação inicial com as experiências profissionais, com os saberes advindos deste fazer e com os conhecimentos obtidos por cursos e programas presenciais ou virtuais. 
Assim, a formação docente, para responder ao compromisso social de uma universidade que prima pela excelência acadêmica no ensino, na pesquisa e na extensão, não pode deixar de enfrentar as urgências próprias da sociedade atual (com seu formidável entorno tecnológico) e o inadiável resgate dos valores próprios do cidadão e da participação da educação escolar nestes desafios.

Não pode também, como nos ensina Silva (2004), deixar de formar um professor com um entendimento radical do currículo como identidade e subjetividade, como possibilidade de problematização da expressão vivencial dos próprios envolvidos no ato educativo. Ou seja: levá-lo a entender e promover uma prática pedagógica comprometida com o ser humano enquanto sujeito sócio-histórico, que leva para a sala de aula uma enorme riqueza de conteúdos propensos ao compartilhamento e ao diálogo com conteúdos já estabelecidos como curriculares.

É preciso, conforme (TARDIF, 2002, p. 23), repensar, agora, a formação para o magistério, levando em conta os saberes dos professores e as realidades específicas de seu trabalho cotidiano. Essa é a ideia de base das reformas que vêm sendo realizadas na formação dos professores em muitos países nos últimos dez anos. Ela expressa a vontade de encontrar, nos cursos de formação de professores, uma nova articulação e um novo equilíbrio entre os conhecimentos produzidos pelas universidades a respeito do ensino e dos saberes desenvolvidos pelos professores em suas práticas cotidianas. Até agora a formação para o magistério esteve dominada, sobretudo, pelos conhecimentos disciplinares, conhecimentos esses geralmente produzidos em uma redoma de vidro, sem nem uma conexão com a ação profissional, devendo, em seguida, serem aplicados na prática por meio de estágios ou de outras atividades de gênero. Atualmente essa visão disciplinar e aplicacionista da formação profissional não tem mais sentido, não somente no campo do ensino, mas também nos outros setores profissionais.

Por isso, a proposta que vislumbramos para a Universidade e as instituições de ensino superior brasileiras deve garantir características inovadoras e ousadas aos processos de formação nos quais estejam assegurados a qualidade social por meio do planejamento e avaliação das ações que se desenvolvem no interior de IES socialmente comprometidas, o ensino superior como direito humano e bem público social,o entendimento das instituições de ensino superior, independentemente de suas dependências administrativas como instituições públicas e a participação da comunidade interna e externa na construção de projetos políticos pedagógicos comprometidos com os interesses e as necessidades das comunidades local, regional, nacional e internacional. 


\section{REFERÊNCIAS}

BICUDO, M. A. V.; SILVA JR., C. (Org.). Formação do Educador: dever do Estado, tarefa da Universidade - 3 volumes. São Paulo: UNESP, 1996 (Seminários e Debates).

BRASIL/MEC/CNE. Lei n. 9.394, de 20 de dezembro de 1996: Diretrizes e Bases da Educação Nacional. Brasília: 1996.

BRASIL/MEC. Proposta de Diretrizes para a formação inicial de professores da educação básica em nível superior. Brasília: 2000.

BRASIL /MEC/ CNE. Proposta de Diretrizes para a formação inicial de professores da educação básica em nível superior. Brasília: 2001.

CONFERÊNCIA MUNDIAL DE EDUCAÇÃO SUPERIOR. UNESCO. Paris, 5-8 de julho de 2009. Disponível em: <http://www.unesco.org > . Acesso em: 20/7/2009.

CURY, C. R. J. Reforma Universitária na Nova Lei de Diretrizes e Bases da Educação Nacional? Cadernos de Pesquisa, São Paulo, n. 101, p. 3-19, jul. 1997.

MICHELOTTO, Regina Maria; COELHO, Rúbia Helena. ZAINKO, Maria Amália Sabbag. A política de expansão da Educação Superior e a proposta de Reforma Universitária do governo Lula. Educar em Revista, n. 28. Curitiba: Ed. UFPR, jul./ dez., 2006.

MIRANDA, G. V. de. Sistemas Educacionais, uma experiência de Minas Gerais, In: HINGEL, M. (Coord.). LDB Reflexões e Caminhos. CBEC: O Desafio da Educação Comunitária. Brasília: INDEC, 1997.

MOREIRA, A. F. B. (Org.). Currículo: questões atuais. Campinas: Papirus, 1997. (Coleção Magistério: Formação e Trabalho Pedagógico).

NÓVOA, A. Para um estudo sócio-histórico e desenvolvimento da profissão docente. Teoria e educação, Porto Alegre, n. 4, p.109-139, 1991.

NÓVOA, A. Os professores: em busca de uma autonomia perdida? In: NÓVOA, A. Ciências da Educação em Portugal - Situação Actual e Perspectivas. Porto: Sociedade Portuguesa de Ciências da Educação, 1991.

NÓVOA, A. Concepções e práticas de formação contínua de professores. In: Formação Contínua de Professores: Realidades e Perspectivas. Aveiro: Universidade de Aveiro, 1991.

NÓVOA, A.; ESTRELA, A. (Org.). Avaliações em Educação: Novas Perspectivas. Lisboa: Educa, 1992. 
NÓVOA, A.; ESTRELA, A. Professores: Imagens do futuro presente. Lisboa: Educa, 2009.

PERRENOUD, P. Práticas pedagógicas, profissão docente e formação. Perspectivas Sociológicas. Lisboa: Dom Quixote, 1993.

PERRENOUD, P. Construir competências desde a escola. Porto Alegre: Artes Médicas Sul, 1999.

PERRENOUD, P. Formar professores em contextos sociais em mudança: prática reflexiva e participação crítica. Revista Brasileira de Educação, v. 12, p. 5 -21, 1999.

PERRENOUD, P. 10 Novas Competências para Ensinar. Porto Alegre: Artes Médicas Sul, 2000.

PERRENOUD, P. Ensinar: agir na urgência, decidir na incerteza. Porto Alegre: Artmed, 2001.

PIMENTA, S. G. Para uma Re-significação da Didática. Ciências da Educação Pedagogia e Didática - uma revisão conceitual e uma síntese provisória. In: VII ENDIPE - ANAIS. Florianópolis: 1996.

PIMENTA, S. G. (Org.). Didática e formação de professores: percursos e perspectivas no Brasil e em Portugal. São Paulo: Cortez, 1997.

SALGADO, M. U. C. Um olhar sobre a formação inicial de professores em serviço. In: VÁRIOS AUTORES. Um Olhar sobre a Escola. Brasília: MEC/SEED, 2000. (Série de Estudos para Educação a Distância).

SAVIANI, D. Os Saberes Implicados na Formação do educador. In: BICUDO, M. A V.; SILVA JR. C. A (Org.). Formação do Educador: dever do Estado, tarefa da Universidade. São Paulo: UNESP, 1996 (Seminários e Debates).

SILVA, T.T. Documentos e Identidade: uma introdução às teorias do currículo. 2. ed. Belo Horizonte: Autentica, 2004.

TARDIF, M. Saberes Docentes e Formação Profissional. 6. ed. Petrópolis: Vozes, 2002.

TARDIFF, M.; LESSARD, C.; LAHAYE, L. Os professores face ao saber: esboço de uma problemática do saber docente. Teoria da Educação, Porto Alegre, n. 4, 1991.

UNESCO. Declaração Mundial sobre a Educação Superior no Século XXI: Visão e Ação. In: ANAIS DA CONFERÊNCIA MUNDIAL SOBRE O ENSINO SUPERIOR - Paris, 5 a 9 de novembro de 1998. Trad. Paris, UNESCO/CRUB, 1998.

VASCONCELOS, M. L. M. C. A Formação do Professor de Terceiro Grau. São Paulo: Pioneira, 1996. 
ZAINKO, M. A. S. Gestão do conhecimento: o desafio da formação inicial e continuada de professores. EDUCERE, PUCPR, Curitiba, 2007, mimeo.

ZAINKO, M. A. S. Educação superior, democracia e desenvolvimento humano sustentável. Curitiba: Champagnat/ INSULAR, 2003.

ZAINKO, M. A. S.; GISI, M. L. (Org.). Políticas e Gestão da Educação Superior. Curitiba: Champagnat/ INSULAR, 2003.

ZAINKO, M. A. S. Seminário Internacional Avaliação Institucional da Educação Superior e reformas do Estado: o desafio da Avaliação das IES. Revista Avaliação, ano 8, v. 8, n. 2, jun. 2003. Campinas.: Unicamp, 2003.

ZAINKO, M. A. S.; COSTA, M. J. J. Avaliação para qual Universidade. Revista Avaliação, ano 9, v. 9- n. 1, mar. 2004. Campinas: Unicamp, 2004.

Texto recebido em 2 de fevereiro de 2010.

Texto aprovado em 8 de março de 2010. 
